\title{
A study of sonosalpingogram compared to laparoscopic chromopertubation in the evaluation of tubal patency
}

\author{
Saley Daniel*, Ashish Bens, Lola Ramachandran
}

Department of Obstetrics and Gynecology, Jubilee Mission Medical College, Thrissur, Kerala, India

Received: 14 October 2016

Accepted: 09 November 2016

\section{*Correspondence:}

Dr. Saley Daniel,

E-mail: drsaleydaniel@gmail.com

Copyright: (c) the author(s), publisher and licensee Medip Academy. This is an open-access article distributed under the terms of the Creative Commons Attribution Non-Commercial License, which permits unrestricted non-commercial use, distribution, and reproduction in any medium, provided the original work is properly cited.

\begin{abstract}
Background: Tubal problems associated with infertility can be due to blocked tubes, adhesion and scarring of the tubes and distal block leading to Hydrosalpinx. The objective of this study is to evaluate the accuracy and efficiency of Sonosalpingography in the assessment of tubal patency, in comparison to the gold standard method of laparoscopic Chromopertubation and to determine its value as a basic non-invasive screening procedure in infertile women.

Methods: A prospective study involving a series of 50 women including both primary and secondary infertility registered in the infertility clinic, Obstetrics and Gynaecology department, at Jubilee Mission Hospital for 1 year (June 2011 to June 2012). These patients after initial evaluation were subjected to sonosalpingography on one of the days between 5th and 10th days of the menstrual cycle for assessment of tubal patency. This was followed by laparoscopy with chromopertubation on the same day or next day. The results of the two tests were compared to determine the accuracy of these SSG.

Results: Mean duration of infertility 6-12 years of standard deviation (SD) from mean of 3.72 years. SE<0.4769 and 95\% CI was 5.6 to 7.079 yrs. Sensitively for tubal patency with SSG compared to Laparoscopic chromotubation was $93.30 \%$ with $95 \%$ CI between 84.77 and 96.85 .

Conclusions: If SSG is performed as a base line test, laparoscopy can be reserved for those women who have unexplained infertility or whose SSG is abnormal or whose medical history and physical examination reveal pelvic pathology.
\end{abstract}

Keywords: Laparoscopy + Chromopertubation, Sonosalpingography, Saline infusion sonography, Transvaginal sonography

\section{INTRODUCTION}

Tubal damage is a common cause of infertility accounting for $14-38 \%$ in the western world and up to $80 \%$ in the developing countries. ${ }^{1-3}$ Tubal problems associated with infertility can be due to blocked tubes, adhesion and scarring of the tubes and distal block leading to hydrosalpinx. The anatomical evaluation of the tubes plays a fundamental role in the workup of infertile couple.
The clinical evaluation of a great number of infertile women (7-16\%) might be based on an evaluation of the risk benefit and cost benefit ratio of diagnostic tools. ${ }^{4-6} \mathrm{~A}$ low cost and low risk methodological approach should be addressed as a first choice investigation, later followed by more complex or invasive procedures. In addition the investigation should provide the clinician with useful prognostic information regarding future treatment. Recent advances in gynaecological ultrasound can replace routine invasive investigative procedures. ${ }^{7}$ This will make the basic infertility investigation less time consuming, less expensive and more acceptable. Transvaginal 
Sonography can give important data about morphologically altered tubes, very infrequently the normal salpinx can be visualized except for the interstitial part. $^{8}$

The gold standard for the diagnosis of tubal disease has been laparoscopy for a long time and any procedure concerning tubal patency testing should be matched to this examination. Laparoscopy requires general anaesthesia and bears the risks bound to surgery. On the other hand, Hysterosalpingography is a valuable tool to asses tubal patency, but it is considered only as an ancillary examination. Hence Sonography based test was introduced in which the tubal patency is established by introducing saline with air into the uterine cavity and imaging the flow of fluid through the tubes and spillage into the peritoneal cavity. ${ }^{9}$ The SSG can be considered as a better option for tubal patency screening as it is a noninvasive procedure, no radiation hazard and no risk of hypersensitivity to contrast agent. It can be done as an office procedure. All infertile patients will be subjected to Transvaginal Sonography, hence introduction of little amount of saline into the uterine cavity along with Transvaginal Sonography will not cause much expense, time or discomfort to the patient.

The aim of the current study was to evaluate the role of saline infusion Sonography in the assessment of tubal patency and compare the results with those obtained during laparoscopy.

After getting Ethical and Research Committee clearance, a prospective study involving a series of 50 women including both primary and secondary infertility registered in the infertility clinic, Obstetrics and Gynaecology department, at Jubilee Mission Hospital for 1 year (June 2011 to June 2012). These patients after initial evaluation were subjected to sonosalpingography on one of the days between $5^{\text {th }}$ and $10^{\text {th }}$ days of the menstrual cycle. This was followed by laparoscopy with chromopertubation on the same day or next day. The results of the two tests were compared to determine the accuracy of SSG.

In all these patients' detailed history with respect to nature and duration of infertility and history suggestive of etiological factors like pelvic inflammatory diseases, tuberculosis and previous surgeries were taken. Menstrual history, past obstetric history in cases of secondary infertility and significant personal and past history were recorded. History regarding male factor infertility was also taken.

The patients were subjected to a general examination, abdominal and pelvic examination to detect any obvious pathology. Routine investigations, husband's semen analysis, and other relevant investigations were done in all these cases.

\section{Inclusion criteria}

Primary and secondary infertility patients, who were willing for tube testing.

\section{Exclusion criteria}

1. Ongoing or recent pelvic infections.

2. Late menses without confirmation of absence of pregnancy.

3. Technical impairment in any of the examinations.

\section{Procedure of SSG}

Informed consent was taken after explaining the procedure and its advantage and complications to the patients, transvaginal sonography was done using 7.5 $\mathrm{MHz}$ vaginal transducer to get a baseline details about the pelvic structures.

Patient was ask to empty the bladder andbrought to the edge table perineum was cleaned, pelvic examination performed to know the size, position and mobility of the uterus. Cuscos speculum was introduced in to the vagina, anterior lip of cervix held with vulsellum, a paediatric foleys catheter ( 8 french) with plastic stillete was introduced into the uterine cavity beyond the internal os, foleys bulb inflated with $2-3 \mathrm{ml}$ of distilled water, to stabilise the catheter within the uterine cavity. At this point patients usually complained of a dull lower abdominal pain. Our policy was to inflate the bulb in the uterine cavity and to pull the foleys from below so that the bulb will snugly fit into the internal os. TVS was done.

Two scanning manueuvers used were:

1. Sagittal view to visualize the entire uterus including the cervix

2. Transverse view $-90^{\circ}$ to the longitudinal axis

During the base line scan, the interstitial part of the salpinx, position of the uterus and ovaries were located. Normally the tube will have an oblique course from the interstitial part of the tube to the medial part of the ovary.

We start the procedure by instilling $3-5 \mathrm{ml}$ of saline with air. This will fill the uterine cavity slowly and any lesions in the cavity will be visualized better. Then about $30-40 \mathrm{cc}$ of sterile saline with air is pushed through the foleys catheter. The scanning is begun from the interstitial part of the salpinx and the hyperechogenicity of air followed laterally towards the ovary by y rotating the probe around the uterine angle. The salpinx can be visualized as a continuous or interrupted line. The tube if patent distends the mixture of saline and air bubbles gush past the ovary to give rise to what is known as the "water fall sign" 
After repeating the procedure on the opposite side, the catheter was deflated and pulled out. Then POD was inspected to see if there is any collection in the POD which will show tubal patency.

\section{Criteria used for tubal patency in the present study}

1. Visualization of the flow of air bubbles in the tubal lumen.

2. Direct visualization of flow of air bubbles around the ovary.

3. Detection of saline in the pouch of Douglas

4. Cornual patency by flow of air bubbles in to the interstitial part of the Salpinx.

In case of cornual block, saline was pushed in short pulses and 2- 3 attempts were tried before declaring it as Cornual block. The mean duration of the whole examination does not exceed 10 minutes.

The patency of each tube at cornual and fimbrial ends were documented and compared with results obtained with laparoscopic chromopertubation.

\section{RESULTS}

There were 50 infertile couple recruited for the study to evaluate the accuracy and efficacy of Sonosalpingography in assessment of tubal patency, in comparison to established gold standard method of laparoscopic chromopertubation.

Table 1: Age wise distribution.

\begin{tabular}{|l|l|}
\hline Age group & Frequency \\
\hline $20-24$ & $\mathbf{1 2}$ \\
\hline $25-29$ & $\mathbf{1 9}$ \\
\hline $30-34$ & $\mathbf{1 5}$ \\
\hline$>35$ & $\mathbf{0 4}$ \\
\hline
\end{tabular}

\section{Age wise distribution}

The average age of the 50 women considered was 27.92 years with a standard deviation (SD) of 4.6 Yrs. Standard error of Mean (SEM) was 0.5749 and the $95 \%$ confidence interval for age is between 26.764 and $29.076 \mathrm{yrs}$.

Table 2: Duration of infertility.

\begin{tabular}{|lll|}
\hline Type & Frequency & Percentage \\
\hline Primary infertility & 28 & $56 \%$ \\
\hline Secondary infertility & 22 & $44 \%$ \\
\hline
\end{tabular}

\section{Duration of infertility}

The mean duration of infertility was around $6.12 \mathrm{yrs}$ in this study with a standard deviation (SD) from mean of 3.372 years. SEM was 0.4769 and the $95 \%$ CI was 5.161 to 7.079 years.

\section{History of tubal damage}

Among the 22 patients who presented with history of secondary infertility , 2 patients had prior ectopic pregnancies of which one was managed with laparoscopic surgery and on our laparoscopic evaluation showed a tube peritoneal fistula which was repaired laparoscopically. The other patient had a patent tube following medical management of the prior ectopic pregnancies. Among the 50 patients evaluated 5 patients gave history suggestive of pelvic inflammatory disease, but none of them gave history of any surgical intervention.

Table 3: Tubal patency.

\begin{tabular}{|lccc|}
\hline Type & Patent & Occluded & Total \\
\hline SSG & 89 & 11 & 100 \\
\hline Laparoscopy & 95 & 5 & 100 \\
\hline
\end{tabular}

Among the 50 patients evaluated 5 patients gave history suggestive of pelvic inflammatory disease, but none of them gave history of any surgical intervention.

One patient with secondary infertility gave history of ovarian torsion after the first child birth, which was managed laparoscopically and on evaluation we found that both tubes were patent.

Among the 100 tubes evaluated. When we plot the findings on a 2 X 2 table we get the following findings.

Table 4: Side effects of SSG.

\begin{tabular}{|c|c|c|c|}
\hline \multicolumn{4}{|c|}{ Gold standard (Laparoscopy) } \\
\hline & Lap Patent & $\begin{array}{l}\text { Lap } \\
\text { Occluded }\end{array}$ & Total \\
\hline SSG Patent & $\begin{array}{l}84 \text { A } \\
\text { (True } \\
\text { Positive) }\end{array}$ & $\begin{array}{l}05 \mathrm{~B} \\
\text { (False } \\
\text { Positive) }\end{array}$ & 89 \\
\hline $\begin{array}{l}\text { SSG } \\
\text { Occluded }\end{array}$ & $\begin{array}{l}07 \mathrm{C} \\
\text { (False } \\
\text { Negative) }\end{array}$ & $\begin{array}{l}04 \mathrm{D} \\
\text { (True } \\
\text { Negative) }\end{array}$ & 11 \\
\hline Total & 91 & 09 & 100 \\
\hline
\end{tabular}

\section{Tubal patency}

Tubal patency was determined using SSG and in the same patient patency was confirmed by performing a diagnostic laparoscopy. 50 patients were included in the study and hence a total of 100 tubes were evaluated.

Among the 100 tubes evaluated there was $93.68 \%$ agreement with regard to tubal patency when compares with laparoscopic chromopertubation.

Among the 50 patients included in the study we find that there was $100 \%$ correlation in 39 of the 50 patients. So 
the rate agreement of SSG with laparoscopy can be calculated at $78 \%$.

\section{Sensitivity}

The sensitivity for tubal patency with SSG compared to laparoscopic chromopertubation is calculated to be 93.302\% with the $95 \%$ CI between 84.77 and 96.85 .

Table 5: Other findings.

\begin{tabular}{|ll|l|}
\hline Findings & SSG & LPS \\
\hline Pelvic adhesions & $\mathbf{3}$ & $\mathbf{9}$ \\
\hline Endometriosis & $\mathbf{5}$ & $\mathbf{7}$ \\
\hline Haemorrhagic cyst & $\mathbf{1}$ & $\mathbf{1}$ \\
\hline Multiloculated clear cyst & $\mathbf{0}$ & $\mathbf{1}$ \\
\hline Poly cystic ovaries & $\mathbf{1 4}$ & $\mathbf{9}$ \\
\hline Hydrosalpinx & $\mathbf{1}$ & $\mathbf{1}$ \\
\hline Adenomyosis & $\mathbf{2}$ & $\mathbf{0}$ \\
\hline Fibroids & $\mathbf{5}$ & $\mathbf{2}$ \\
\hline Polyp & $\mathbf{1}$ & $\mathbf{1}$ \\
\hline Tubuperitoneal fistula & $\mathbf{0}$ & $\mathbf{1}$ \\
\hline
\end{tabular}

\section{Specificity}

The Specificity of tubal patency testing is calculated to be $44.4 \%$ with the $95 \%$ CI between 13.69 and 78.29 .

\section{Positive predictive value (PPV)}

In this study the Positive Predictive Value PPV of SSG when compared with the gold standard laparoscopy if $94.382 \%$.

\section{Negative predictive value (NPV)}

In this study the negative predictive value (NPV) of SSG compared to laparoscopy was $36.3 \%$.

Prediction of tubal patency is high in SSG whereas prediction of tubal block is not as accurate as tubal patency. Of the 11 tubal occlusions diagnose only 5 were actually having block. So we assume that if tubal occlusion is suspected in SSG, it warrants a laparoscopic evaluation to confirm the same and intervene, if required.

Table 6: Results of gold standard (Laparoscopy).

\begin{tabular}{|ll|}
\hline Side effects & Frequency \\
\hline Moderate to severe Pelvic Pain & 4 \\
\hline Vaso vagal symptoms & \\
\hline Fainting & 1 \\
\hline Hypotension & 1 \\
\hline Bradycardia & 2 \\
\hline Sweating & 4 \\
\hline Nausea & 5 \\
\hline Vomiting & 2 \\
\hline
\end{tabular}

SSG could not detect all the pelvic adhesions, whereas laparoscopy can detect all of them and adhesiolysis can also be done at the same time. Small endometriotic deposits are better seen on laparoscopy than SSG.

\section{DISCUSSION}

Tubal disease is one among the most frequent cause of female infertility. It may be present in up to $25-30 \%$ of the patients. In the infertile patient, transvaginal sonography is widely used as a means to evaluate the morphology of inner genital tract and to monitor follicular development in stimulated and natural cycles. ${ }^{10}$ Transvaginal sonography can give important data about the morphologically altered tubes, but infrequently the normal salpinx can be visualized.

Table 7: Characteristics of SSG (and HyCoSY) versus HSG and laparoscopy to test tubal patency.

\begin{tabular}{|c|c|c|}
\hline $\begin{array}{l}\text { SSG or } \\
\text { HyCoSy }\end{array}$ & HSG & $\begin{array}{l}\text { Laparoscopy with } \\
\text { Chropertubation }\end{array}$ \\
\hline $\begin{array}{l}\text { Visualization } \\
\text { of pelvic or } \\
\text { ovarian cysts }\end{array}$ & & $\begin{array}{l}\text { Dirct visualization } \\
\text { of the abdominal } \\
\text { cavity }\end{array}$ \\
\hline $\begin{array}{l}\text { Good } \\
\text { depiction of } \\
\text { the uterine } \\
\text { cavity }\end{array}$ & $\begin{array}{l}\text { Excellent } \\
\text { depiction of } \\
\text { the uterine } \\
\text { cavity and of } \\
\text { the tubal lumen }\end{array}$ & \\
\hline $\begin{array}{l}\text { No surgical } \\
\text { risks }\end{array}$ & No surgery & Surgical risks \\
\hline $\begin{array}{l}\text { No } \\
\text { anaesthesia }\end{array}$ & No anaesthesia & $\begin{array}{l}\text { General } \\
\text { Anaesthesia }\end{array}$ \\
\hline $\begin{array}{l}\text { No allergic } \\
\text { reaction }\end{array}$ & $\begin{array}{l}\text { Allergic } \\
\text { reaction to } \\
\text { iodinated } \\
\text { media }\end{array}$ & \\
\hline Low cost & Higher cost & Highest cost \\
\hline $\begin{array}{l}\text { No exposure } \\
\text { to radiation }\end{array}$ & $\begin{array}{l}\text { Radiation } \\
\text { exposure }\end{array}$ & No radiation \\
\hline Outpatient & Outpatient & Inpatient \\
\hline
\end{tabular}

The gold standard for the diagnosis of tubal diseases has been laparoscopy for a long time and any procedure concerning tubal patency should be matched to this examination.

Coming to the historical development of the technique of tubal patency tests by sonography, it was started in early eighties when attempts have been made to show the patency by injecting echo free contrast agent, such as saline into the uterine cavity. ${ }^{11-12}$ With the advent of high resolution USG machine the diagnosis of tubal patency is made easy and non-invasive using saline as a contrast agent. The patient comes in the first half of the cycle, before ovulation. Normally preferred period is the very beginning of the cycle because the cervical canal is not 
filled with mucus and the catheter is less frequently expelled from the cervix. SSG is used on a clinical basis as an outpatient procedure. ${ }^{13-16}$

A prospective study at Al-Azhar university hospital, Cairo, Egypt and Hadi Hospital, a private hospital in Kuwait.

All women underwent HSG, TV-SH and diagnostic laparoscopy. The aim of the above study was to evaluate the role TV-SH in the assessment of tubal patency and to compare these results with those obtained using HSG and laparoscopy.

Table 8: Procedure related difficulties and suggestions for the solution.

\begin{tabular}{|c|c|c|}
\hline Difficulty & Cause & Solution \\
\hline \multirow[t]{2}{*}{$\begin{array}{l}\text { Catheter } \\
\text { introduction }\end{array}$} & $\begin{array}{l}\text { Severe } \\
\text { angulations of } \\
\text { cervix }\end{array}$ & $\begin{array}{l}\text { Traction of the } \\
\text { cervix by a single } \\
\text { tooth } \\
\text { tenaculaum, } \\
\text { appropriate use } \\
\text { of speculum }\end{array}$ \\
\hline & Cervical stenosis & $\begin{array}{l}\text { Use of Hegars } \\
\text { dilator and } \\
\text { suitable catheter }\end{array}$ \\
\hline \multirow[t]{2}{*}{$\begin{array}{l}\text { Uterine cavity } \\
\text { distension }\end{array}$} & $\begin{array}{l}\text { Cervical } \\
\text { incompetence } \\
\text { with solution } \\
\text { reflux }\end{array}$ & $\begin{array}{l}\text { Use of catheter } \\
\text { with a balloon } \\
\text { inflated at the } \\
\text { cervical internal } \\
\text { os }\end{array}$ \\
\hline & Uterine myoma & \\
\hline $\begin{array}{l}\text { Low } \\
\text { tolerance of } \\
\text { procedure }\end{array}$ & $\begin{array}{l}\text { Low pain } \\
\text { threshold } \\
\text { Endometriosis } \\
\text { Chronic pelvic } \\
\text { pain syndrome } \\
\text { Fear of the } \\
\text { examination }\end{array}$ & $\begin{array}{l}\text { Use of para } \\
\text { cervical block } \\
\text { analgesia } \\
\text { Aspiration of } \\
\text { saline after } \\
\text { procedure } \\
\text { NSAID } \\
\text { Patient } \\
\text { counselling }\end{array}$ \\
\hline
\end{tabular}

The sonographic examinations were carried out using Creds (combison) 410 plus, with multi frequency convex transvaginal probe and a frequency range of $5: 7.5 \mathrm{MHz}$ transducer. There was no significant difference between all the 3 groups. The total compatibility between the laparoscopic and HSG findings was $87 \%$ and between the laparoscopic and SSG findings was $94.1 \%$ the differences were statistically insignificant.

HSG is still an important diagnostic procedure to evaluate tubal patency. ${ }^{15}$ HSG allows documentation of tubal patency, enables detection of several tubal lesions and permits assessments of fine intratubal architectural details, especially when an aqueous contrast medium is used. ${ }^{17-19}$ In the above study, the HSG findings showed that the incidence of tubal block in primary infertility was found $50 \%$ and in secondary infertility was $60 \%$. These results were in agreement with the previous studies. ${ }^{20-24}$ Kenufa $\mathrm{O}$ et al reported that HSG and laparoscopy were compatible in diagnosis of intratubal and distal tubal occlusion. This present study was in agreement with the results of previous studies by Allahabadia, who reported more than $90 \%$ compatibility between SSG and laparoscopy. ${ }^{25-29}$ Heikkinen et al and Inki et al reported similar results. ${ }^{30}$ Mitri et al and Tufekii reported in their studies similar conclusion regarding the accuracy of SSG is a simple technique and should replace the use of HSG. ${ }^{31,32}$ The disadvantage of the procedure is that it cannot demonstrate with accuracy the proximal part of the tube especially the corneal area.

In a series of 50 women investigated by Donnez et al, these techniques gave comparable information regarding tubal patency in $90 \%$ of cases.

\section{SSG - advantages}

1. It is an office procedure, less time consuming and cost effective.

2. It is a noninvasive procedure.

3. No anaesthesia required.

4. It helps in diagnosing both uterine anomalies and pelvic pathology

5. It can be used to detect tubal patency during postoperative hydro tubation following tube reconstructive operation

6. No radiation hazards are involved.

\section{SSG - disadvantages}

1. Site of tubal block cannot be determined.

2. Intra tubal pathology cannot be visualized.

3. Peritubal adhesions and mobility of the tube cannot be properly assessed.

4. There are false positive results in cases of massive hydrosalpinx.

5. Findings are subjective.

They concluded that SSG is not a substitute for established tests like HSG or laparoscopy, but it can be done as screening test in the initial work up of infertile women. Laparoscopy and HSG can be differed in a patient whom SSG showed patent tubes thus allowing them to concentrate on other factors for infertility.

In patients with negative or suspicious findings on SSG, HSG or laparoscopy can be used for confirmation.

At the department of OBG, Tueku University, central Hospital, Finland, 32 patients suffering from primary and secondary infertility were evaluated for tubal patency with SSG using paediatric foley's urinary catheter and a combination of air and saline solution as a contrast medium. 4 patients conceived before their scheduled 
laparoscopy and were excluded from the study. In addition, the patency of 3 fallopian tubes could not be adequately evaluated, leaving altogether 53 uterine tubes that were evaluated by both methods (Laparoscopy and SSG). The findings of both methods agreed in 47 out of 53 tubes (concordance $88.7 \%$ ). The sensitivity of SSG in diagnosing tubal patency was $90.2 \%$ and the specificity was $83.3 \%$. The PPV for tubal patency by HSG was $94.9 \%$ and the NPV was $71.4 \%$.

The evaluation of tubal patency is traditionally considered fundamental in the study of infertility and it represents $1 / 3^{\text {rd }}$ of the total cost in the management of infertile couples. Doubts about SSG utility in the study of tubal patency still exist. The results obtained show how the accuracy of this methodology is at the same level of HSGs, when the two techniques are compared with laparoscopic chromopertubation.

According to the literature, this study confirms that HSG is a technique that presents considerable number of false results that lead inevitably to laparoscopy whilst, on the contrary, SSG has lower false positive results. Moreover it is important to notice that in the sample analysed, SSG never failed the presence of a bilateral tubal occlusion. Generally the pathologic findings are easily detectable, even by a less experienced sinologist by looking the absence of fluid in the POD after a few minutes.

MOI documented how in a population of women who underwent HSG, only the bilateral tubal occlusion was strongly correlated with a low percentage of pregnancy $(0.30 \%)$, while the fecundity rate ratio between women without tubal pathology and women with monolateral occlusion was almost equal.

A recent study stated that HDS technique can be considered the most accurate test in the evaluation of uterine cavity disease in infertile women and in particular in cases of polypoid lesions. ${ }^{33}$ Goldberg found that in the evaluation of patients with infertility or recurrent pregnancy loss and uterine abnormalities on HSG, HDS was more accurate than HSG and provided additional information about uterine abnormalities particularly on the relative proportion of the intracavitary and intramyometrial components of submucous myomas as well as extra cavitary myomas and the adnexal pathology. ${ }^{34,35}$ Later concerning the appearance of uterine cavity, Darwish confirmed that HDS agreed with hysteroscopy in $72.2 \%$ of cases, while the appearance of tubes obtained using HDS agreed with laparoscopy in $72.4 \%$ of cases ( $\mathrm{R}$ tube) and $60.5 \%$ (L tube). ${ }^{36}$ Using the direct indicator of tubal patency as the appearance of fluid in pouch of Douglas the agreement between SSG and laparoscopy rise to $88.1 \%$ (one tube) and to $85.7 \%$ (both). Also in the evaluation of abnormal uterine bleeding HDS seems to have an important role. ${ }^{37,38}$

\section{Other indications for SIS}

SIS is a diagnostic procedure that enhances endometrial imaging by using saline as a contrast medium. It has been used in conjunction with traditional transvaginal sonography to aid the diagnosis of uterine and endometrial abnormalities including:-

1. DUB

2. Infertility

3. Recurrent abortion

4. Suspected Asherman Syndrome

5. Patients receiving tamoxifen therapy

\section{Indications for SSG}

SSG should not be performed in a woman who is pregnant or could be pregnant. This is usually avoided by scheduling the examination in the follicular phase of the menstrual cycle after menstrual flow has essentially ceased but before the patient has ovulated. In patients with regular cycles, it is performed on the tenth day of the cycle. SSG should not be performed in patients with a pelvic infection or unexplained pelvic tenderness. Active vaginal bleeding is not a contraindication to the procedure but may make the interpretation more challenging. The referring physician may elect to prescribe a prophylactic antibiotic if patients routinely take these for other invasive procedures. If painful, dilated or obstructed fallopian tubes are found prior to injection and the patient is not taking antibiotics, the examination should be delayed. Patients should be questioned about latex allergy prior to use of a latex sheath.

\section{CONCLUSION}

SSG is a much less invasive procedure than laparoscopy and yields valuable information in infertile couple. All infertile women have to be subjected to transvaginal sonography for basic evaluation as well as for follicular monitoring. Instilling little amount of saline, while doing transvaginal sonography will not add much to the cost of procedure.

- $\quad$ Time taken for the procedure is only 20-25 minutes.

- There is not much side effect to the patient other than mild discomfort.

- It can be done as an outpatient procedure.

- No need of anaesthesia.

- No risk of hypersensitivity to contrast agents as saline is used as the contrast agents.

- No risk of exposure to radiation hence can be repeated if there is suspicion.

- No risk of exposure to the person who is performing the procedure.

- Additional information other than patency regarding cervical, endometrial and adnexal pathology was obtained. 
If SSG is performed as a base line test, laparoscopy can be reserved for those women who have unexplained infertility or whose SSG is abnormal or whose medical history and physical examination reveal pelvic pathology.

Funding: No funding sources

Conflict of interest: None declared

Ethical approval: Not required

\section{REFERENCES}

1. Dor J, Homburg R, Raban E. An evolution of etiologic factors and therapy in 665 infertile couples. Fertil Steril. 1977;28:718-22.

2. Klinger BE. Evaluation, therapy and outcome in 493 infertile couples. Fertil Steril. 1984;41:40-6.

3. Mosher WD, Pratt WF. Fecundity and infertility in the United States: incidence and trends. Fertil Steril. 1991;56:192-3.

4. Tempelton A, infertility and the establishment of pregnancy - overview, Br Med Bull. 2000;56:57787.

5. Bucket W, Bentick B. The Epidemiology of infertility in a rural population. Acta obstet Gynecol. 1997;76:233-7.

6. Miller JH, Weinburg RK, Canino NL, Klein NA, Soules MR. The pattern of infertility diagnosis in women of advanced reproductive age. Am J Obstet Gynecol. 1999;181:952-7.

7. Case AM, Pierson AM. Clinical use of SHG in evaluation of infertility. J Obstet Gynecol Can. 2003;25(8):641-8.

8. Malhotra N, Malhotra J. Sonosalpingography. Obstet Gynaecol. 2006;1(2):71-3.

9. Heikkinen H, Tekay A, Volpi E, Martikainen H, Joupilla P. Salpingosonography for the assessment of tubal patency in infertile women: Methodological and clinicl experiences.Fertil Steril. 1995.

10. Peters AJ, Coulam CB. Hysterosalpingography with colour Doppler Ultrasonography.Am J Obstect Gynecol. 1991:164;1530-4.

11. Stern J, Peters AJ, Coulam CB. Colour Doppler Ultrasonography Assessment of tubal patency. A comparison study with traditional techniques. Fertil Steril. 1992;58:897-900.

12. Yarali H, Gurgen T, Erden A, Kisnisci HA. Colour Doppler hysterosalpingography; A simple and potentially useful method to evaluate fallopian tube patency. Hum Reprod. 1994;9(1):64-6.

13. Campell S, Bourne TH, Tan SL, Collins WP. Hysterosalpingo Contrast sonography (HyCoSy) and its future role within the investigation of infertility in Europe. Ultrasound Obstet Gynecol. 1994;4:245-53.

14. Venezia R, Zangaraa C. Echohysterosalpingography new diagnostic possibilities with S HU 450 Echovist, Acta Europe. Fertil Steril. 1991;22:279-82.

15. Suttipichate J, Sroywattana C. Transvaginal Saline Sonosalpingography for the evaluation of tubal patency. Thai Journal of Obstetrics and Gynecology. 2002;14:223-9.
16. Seal SL, Ghosh D, Saha D, Battacharya AR, Gosh S, Mitra S. Comparative Study of SSG, HSG and Laparoscopy in the evaluation of tubal patency. J Obstet Gynecol. 2007;57(2):158-61.

17. W.H.O. comparative trial of tubal insufflations, hysterosalpingography, and laparoscopy with dehydrotubation for assessment if tubal patency. Fertil Steril. 1986: 46;1107-1107.

18. Wiedemann R, Rosec T, Stuckensen J, Hepp H. Die transuterine eileitersondierung eine wenig invasive ambulat durchzufuehrende Ueberprfung der Eiter durchgaengigkeit. Geburts U Frauenheik. 1994;54;39-46.

19. Lissie K, Sydow P. Fallopian tube catheterization and recanalisation under ultrasonic observation; a simplified technique to evaluate tubal patency and open proximally obstructed tubes. Fertil Steril. 1991;56;198-201.

20. Stern JJ, Peters AJ, Coulam CB. Transcervical tuboplasty under ultrasonographic guidance: a pilot study. Fertil Steril. 1991;56:359-60.

21. Dessole S, Farina M, Rubattu G. Side effects and complications of sonohysterosalpingography. Fertil Steril. 2003;80;620-4.

22. Maroulis GB, Parson Ak, Yeko TR. Hydrogyneacography; a new technique enables vaginal sonography to visualise pelvic adhesions and other pelvic structure. Fertil Steril. 1992;58:1073-5.

23. Standell A, Bourne T, Bergh C. Assessment of endometrial pathology and tubal patency; a comparison between the use of ultrasonography and $\mathrm{X}$-ray hysterosalpingography for the investigation of infertility patients. Ultrasound obstet Gynecol. 1994;14:200-4.

24. Bacervac J, Ganovic R. diagnostic value of hysterosalpingography in examination of fallopian tube in infertile women(abstract). Srpski Arhiv za Celokupno Lekarstvo. 2001;129(1-2):18-21.

25. Spalding H, Martikainen HA. A randomized study comparing air to Echovist as a contrast medium in the assessment of tubal patency in infertile women using transvaginal salpingosonography. Human Reprod. 1997;12(11):2461-4.

26. Spalding H, Perälä J, Martikainen H. Assessment tubal patency with transvaginal salpingosonography after the reversal of tubal ligation for female sterilization. Human Reprod. 1998;13(10):2819-22.

27. De Almeida I, Souza C, Facin A, Lavic Y, Passos EP. Hystero sonosalpingography and hysterosalpingography in the diagnosis of tubal patency in infertility patients. Rev Assoc Med Bras. 2000;46(4):342-5.

28. Inki P, Palo P. Vaginal sonosalpingography in the evaluation of tubal patency. Acta Obstet Gynecol Scanned. 1998;77 (10):978-82.

29. Heikkinen H, Tekay A, Volpi E. Trasnvaginal Salpingography for the assessment of tubal patency in infertile women; Methodological and clinical experiences. Fertil Steril. 1995:64(2):293-8. 
30. Zuo W, Wang P. Comparative study on assessment of tubal patency among tubal insufflations, hydrotubation, hysterosalpingography and chromotubation under laparoscopy. Zhonghua FU Chan Ke Za Zhi. 1996;31(1):29-31.

31. Omigbodun AO, Fatukasi JI, Abudu T.Ultrasonography as an adjunct to hydrotubation in the management of female infertility. Central African Journal of Medicine. 1992;38(8):345-50.

32. Soares SR. Diagnostic accuracy of sonohysterography, transvaginal sonography and hysterosalpingography in patients with uterine cavity disease. Fertil Steril. 2000;73:406-11.

33. Goldberg JM, Falcone T. Sonohysterographic evaluation of uterine abnormalities noted on hysterosalpingography. Human Reproduction. 1997;12(10):2151-3.

34. Darwish AM, Youssef AA. Screening sonohysterography in infertility. Gynecol Obstet Invest. 1999;48:43-7.

35. Descargues G, Lemercier E, David C, Genevois A, Lemoine JP, Marpeau L. Which intial test should be performed to evaluate meno-metrorrhagiav? a comparison of hystrography transvaginal sonography and hysteroscopy. J Gynecol Obstet Boil Reprod. 2001;30:59-64.

36. Ashley Hill D. Sonohysterography in the office, instruments and technique. Comtemporary OB/Gyn Archieve. 1997:15.

37. van Roessel J. Sonographic investigation of the uterus during artificial cavity distenstion. J Clin ultrasound. 1987; 15:439-50.

38. Syrop CH, Sahakian V. Transvaginal sonographic detection of endometrial polyps with fluid contrast augmentation. Obstet Gynecol. 1992;79:1041.

Cite this article as: Daniel S, Bens A, Ramachandran L. A study of sonosalpingogram compared to laparoscopic chromopertubation in the evaluation of tubal patency. Int J Reprod Contracept Obstet Gynecol 2016;5:4453-60. 